\title{
Postpartum Depression and Marital Relationship
}

\author{
Daniela Meçe ${ }^{1}$ \\ Aleksander Moisiu University, Durres, Albania \\ E-mail: danielamece@gmail.com
}

Doi:10.5901/ajis.2013.v2n4p319

\begin{abstract}
Three hundred-ninety-eight new mothers, from one month postpartum to one year post partum were part of this study. The study was conducted in Tirana. The aim of this study is to explore postpartum depression (PPD) and the factors that can contribute to PPD, with an emphasis on marital relationship. Edinburgh Post Natal Depression Scale and the revised version of Beck Postpartum Depression Predictors Inventory (PDPI - R) were used in this study to evaluate women with PPD and factors contributing to PPD. Approximately $23 \%$ of women that used the Edinburg Postpartum Depression Scale were found to have PPD.To evaluate the relationship between Postpartum Depression and marital relationship is used Pearson correlation. Postpartum depression and marital relationship were negatively moderately correlated at a significant level.
\end{abstract}

Keywords: Postpartum depression, marital relationship

\section{Introduction}

Having a child is a time of biological, psychological, and social change in a woman's life. These changes can contribute to personal growth and happiness, but they may also predispose women to emotional distress. The postpartum period represents one of the most important life stages in which the accurate detection and treatment of psychological distress is required. It involves changes in relationships between couples and within families, and is commonly a cause of additional stress.

\subsection{Postpartum Depression}

Postpartum Depression (PPD) is a depression episode that begins within 6 months after birth and matches the criteria of DSM - IV for major depression without psychotic consequences (APA, 1994). The prevalence of PPD is about 8-35\% depending on the method used for evaluation (Milgrom et al., 2006). PPD occurs when there is an increase in demands on a new mother due to the child development.

Characteristic symptoms of PPD are similar to those of major depression, including sadness, despair, anxiety, compulsive thoughts, and appetite and sleep disturbances. Furthermore, a new mother may have thoughts of harming herself and/or her infant ( Centers for Disease Control and Prevention 2010). In addition to directly affecting a new mother's mental health, PPD can interfere with a mother's ability to recognize and respond to the needs of her infant, increasing the risk for infant delays in development and behavioral problems in childhood (Horowitz and Goodman 2005). Consequently, PPD is considered a major form of depression that requires treatment and identifying women who may be at an increased risk for developing

1 Daniela Mece is a lecturer of Psychology Department, Faculty of Education in Durres University. Any inquires related to this study can be sent to her email address: danielamece@gmail.com 
postpartum depression is crucial. Lack of diagnosis of PPD can affect the mother, her child, family, and society through social dysfunction, illness, and death or treatment costs. (Mrazek \& Haggarty, 1994)

\subsection{Marital relationship and marital satisfaction}

Several well designed studies (Braverman \& Roux, 1978; Kumar et al., 1984) have reported an increased risk of postpartum depression in women who experience marital problems during pregnancy. Hopkins et al.(1987) however failed to confirm this finding. Women with postpartum depression perceived their husbands to be less supportive than women who were not depressed, but these differences were apparent only postpartum and not during pregnancy (O'Hara, 1986; O'Hara et al., 1983).

Beck, O'Hara and Swain assessed marital relationship in meta analyses. Beck (2001) included 14 studies comprising over 1500 subjects, while O'Hara and Swain (1996 ) included 8 studies of over 950 subjects.

Beck found a moderate association between poor marital relationship and postpartum depression, whilst O'Hara and Swain reported a small negative relationship.

It was interesting that differing methods of assessment produced different effect sizes. Marital relationship assessed via interviews was not as predictive as when measured via self -report. The reason for this is unclear, but may relate to reluctance to discuss the nature of the relationship with an interviewer, but through the anonymity of a questionnaire it is easier. It could also reflect increased sensitivity within questionnaire measures (WHO 2003).

Relationship satisfaction is typically highest during early marriage and tends to decrease after the birth of the first child (Medina \& Magnuson, 2009). The transition to parenthood has been identified as the potential cause of a general increase in marital conflict and a decrease in marital satisfaction (Lawrence at al., 2008). Relationship satisfaction is particularly important to consider among postpartum parents because it influences positive mother and father co-parenting behaviors toward young infants and generally promotes positive health outcomes within relationship dyads (Robles at al., 2003).

\subsection{The purpose of the study}

The main purpose of this study was to explore postpartum depression in Tirana and the predictors of PPD focusing on impact of marital relationship. The results from this study will contribute to a better understanding of this problem. In Albania there is a lack of studies regarding postpartum depression, therefore a better understanding of the factors that affect women's experiences with PPD will serve for early identification of symptoms and early treatment of mothers, children, and families.

\section{Methodology}

\subsection{Methods}

Edinburgh Postnatal Depression Scale (EPDS) is used for PPD screening. EPDS is one of the best standardized questionnaires used to assess PPD (Cox at al. 1987). Built with 10 self reported questions, EPDS has shown high levels of reliability and validity.

The revised version of Beck Postpartum Depression Predictors Inventory (PDPI- R) was used to elicit information on the risk factors related to PPD. The PDPI-R is an inventory that evaluates eight risk factors found to be significantly related to postpartum depression; marital relationship/satisfaction is one of them (Beck 2001). 


\subsection{Sample}

A sample of 398 women was part of this study. They were all woman one month to one year post partum who attended primary child health centers in Tirana.

\subsection{Procedure and Data Collection}

Study conducted from July to December 2012 in primary child health centers of Tirana. Questionnaires were conducted in private rooms, suitable for the participants and the researcher, after the informed consent was taken from participants.

\subsection{Analysis}

The data was analyzed using the Statistical Package for the Social Sciences (SPSS Version 16.0 for Windows). The data collected through the questionnaire was subject to descriptive statistics.

\section{Results}

Most of the interviewed mothers were 21 - 30 years old (60\%), and $99 \%$ of them were married. Fifty - six percent had their first child and $48 \%$ had a university degree. Twenty-seven percent $(n=109)$ reported that the pregnancy was unplanned and only $7 \%$ indicated the pregnancy was unwanted $(n=29)$. After delivery $17 \%$ of the mothers reported health complications for themselves and $8.3 \%$ reported complications for their new born.

Table 1 indicates that approximately $23 \%$ of sampled women had results indicating PPD. This data was collected using the EPDS. In this study EPDS was found to be highly reliable (10 items; $\alpha=.84$ ). However, a clinical diagnosis is necessary for a clearer assessment of PPD.

Table 1: Postpartum Depression

Postpartum Depression

\begin{tabular}{|c|c|c|c|c|c|}
\hline & & Frequency & Percent & Valid Percent & Cumulative Percent \\
\hline \multirow[t]{3}{*}{ Valid } & No Depression & 305 & 76,6 & 76,6 & 76,6 \\
\hline & Depression & 93 & 23,4 & 23,4 & 100,0 \\
\hline & Total & 398 & 100,0 & 100,0 & \\
\hline
\end{tabular}

To evaluate the relationship between Postpartum Depression and marital relationship is used Pearson correlation. As it is seen in Table 2, Post partum depression and marital relationship were negatively moderately correlated at a significant level; $\quad r(397)=-.36, P<.01$. 
Table 2: Postpartum Depression and Marital Relationship correlation

\begin{tabular}{llll} 
Correlations & & & \\
\hline \hline & & DPP & Marital Relationship \\
\hline DPP & Pearson Correlation & 1 &,$- 363^{* *}$ \\
& Sig. (2-tailed) &, 000 \\
& $\mathrm{~N}$ & 398 & 397 \\
\hline Marital Relationship & Pearson Correlation &,$- 363^{* *}$ & 1 \\
& Sig. (2-tailed) &, 000 & \\
& $\mathrm{~N}$ & 397 & 397 \\
\hline \hline
\end{tabular}

**. Correlation is significant at the 0.01 level (2-tailed).

The relationship between PPD and recently stressful life events was evaluated. Study participants selected one or more of these stressful life events: Financial problems, marital problems, death in family, serious illness in the family, moving, unemployment and job change.

One of the most stressful life events selected by the participants was financial problems, but results indicate that PPD has a strong relationship with marital problems.

\section{Discussion}

The postpartum period represents one of the most important life stages in which the accurate detection and treatment of psychological distress is required. This study offers important information about PPD and how marital relationship may affect it.

According to Milgrom et al. the prevalence of PPD is about 8-35\% depending on the method used for evaluation (Milgrom et al., 2006). In the present study $23 \%$ of new mothers had signs of PPD. Results indicate a high prevalence of postpartum depression in Tirana. The lack of studies related to PPD in Albania makes it difficult to have a clear representation of the problem. It should be noted that this is only a prediction of PPD and that a clinical diagnosis is needed for a clearer assessment.

Beck (2001) found a moderate association between poor marital relationship and postpartum depression. Consistent with the findings from prior studies, the results suggest that depressed mothers have poorer ratings of their marital relationship and marital satisfaction. Marital problems seem to be one of the most stressful events relating to postpartum depression mothers.

The study doesn't explain if poor marital relationship cause PPD or the PPD mother perception for her marital relationship is influenced by her depression.

A limitation of this study is that fathers were not included. Without proper understanding of both parents' mental and relationship health, any conclusions about how maternal relationship satisfaction changes as a function of PPD are limited.

This study used PPDI-R, a 3-item measure marital satisfaction/relationship. It is possible that this brief assessment of mothers' perceptions is not the best method to fully measure marital relationship.

The current study results make us believe that the provision of adequate postpartum care is crucial in the identification of emotional distress. Considering the high prevalence of PPD during the mothers' postpartum period, these kinds of studies are crucial for early identification of symptoms and early treatment of mothers, children, and families. 


\section{References}

APA.(1994). Diagnostic and Statistical Manual of Mental Disorders (4th edn). American Psychiatric Association, Washington, D.C.

Beck, C. T. (1996). A meta-analysis of p.redictors of postpartum depression. Nursing Research, 45, 297-303

Beck, C. T. (2001). Predictors of postpartum depression: an update. Nursing Research, 50, 275-285.

Braverman, J. \& Roux, J. F. (1978). Screening for the patient at risk for postpartum depression. Obstetrics and Gynecology, 52, 731-736.

Brown, G. W. \& Harris, T. (1978). Social Origins of Depression: A Study of Psychiatric Disorder in Women. New York: The Free Press.

Centers for Disease Control and Prevention. 2010. "Depression Among Women of Reproductive Age and Postpartum Depression." Retrieved March 1, 2012 (HYPERLINK"http://www.cdc.gov/reproductivehealth/Depression/"). 30(2):101-08

Cox JL, Holden JM, Sagovsky R.(1987). Detection of postnatal depression: Development of the 10-item Edinburgh Postnatal Depression Scale. Journal of Psychiatry. ;150:782-786

Hopkins, J., Campbell, S. B., \& Marcus, M. (1987). Role of infant-related stressors in postpartum depression. Journal of Abnormal Psychology, 96, 237-241.

Horowitz, June Andrews and Janice H. Goodman. 2005. "Identifying and Treating Postpartum Depression." Journal Of Gynecologic \& Neonatal Nursing. 34(2): 264-73. International Review of Psychiatry, 8, 37-54.

Kumar, R. \& Robson, K. M. (1984). A prospective study of emotional disorders in childbearing women. British Journal of Psychiatry, 144, 35-47. Canberra: NHMRC.

Lawrence, E., Rothman, A., Cobb, R., Rothman, M., \& Bradbury, T. (2008). Marital satisfaction across the transition to parenthood. Journal of Family Psychology, 22, 41-50.

Medina, S., \& Magnuson, S. (2009). Motherhood in the 21st century: Implications for counselors. Journal of Counseling \& Development, 87, 90-97.

Milgrom, J., Ericksen, J., McCarthy, R., \& Gemmill, A. (2006). Stressful impact of depression on early mother-infant relations. Stress \& Health: Journal of the International Society for the Investigation of Stress, 22(4), 229-238

Mrazek P.J., Haggarty R.J. (1994).Reducing risks for mental disorders: frontiers for preventive intervention research. IOM. The National Academy of Sciences, United States of America.

O'Hara, M. W. \& Swain, A. M. (1996). Rates and risk of postpartum depression-a meta-analysis. International Review of Psychiatry, 8, 37-54.

O'Hara, M. W. (1986). Social support, life events, and depression during pregnancy and the puerperium. Arch.Gen.Psychiatry, 43, 569-573.

O'Hara, M. W., Rehm, L. P., \& Campbell, S. B. (1983). Postpartum depression. A role for social network and life stress variables. J.Nerv.Ment.Dis., 171, 336-341.

Robinson GE, Stewart DE.( 2001) Postpartum disorders. In: Stotland NL,Stewart DE, editors. Psychological aspects of women's health care.Washington (DC), American Psychiatric Press, Inc. 117-39

Robles, T. F., \& Kiecolt-Tlaser, J. K. (2003). The physiology of marriage: pathways to health. Physiology \& Behavior, 79, 409-416. 